\title{
APLICAÇÃO DO BALANCED SCORECARD NO AUXÍLIO À FORMULAÇÃO DO PLANEJAMENTO ESTRATÉGICO NO SETOR PÚBLICO: O CASO DAE/UFLA
}

\section{APPLICATION OF THE BALANCED SCORECARD IN SUPPORT THE DEVELOPMENT OF STRATEGIC PLANNING IN THE PUBLIC SECTOR: THE CASE DAE / UFLA}

\begin{abstract}
Alan Gabriel Fernandes Departamento de Administração e Economia da Universidade Federal de Lavras (MG) - UFLA alan@dae.ufla.br

Renata Pedretti Morais Furtado

Departamento de Administração e Economia da Universidade Federal de Lavras (MG) - UFLA renata@dae.ufla.br
\end{abstract}

Patrícia Aparecida Ferreira Departamento de Administração e Economia da Universidade Federal de Lavras (MG) - UFLA paf@dae.ufla.br

Submissão: $27 / 10 / 2015$

Aprovação: 30/12/2015 


\title{
RESUMO
}

Atualmente, um dos principais objetivos das organizações é alcançar melhorias no desempenho organizacional. Ao mesmo tempo, elas estão inseridas em um contexto de incertezas e complexidade que exige flexibilidade frente às exigências e às transformações do ambiente. Neste contexto, a elaboração de um planejamento estratégico adequado às características e pretensões da organização é essencial. O BSC é uma metodologia que auxilia na formulação do planejamento e na definição de objetivos estratégicos para as organizações, sejam elas do setor privado ou público. Assim, este estudo busca fazer uso desta metodologia para desenvolver propostas de objetivos para um departamento didático pedagógico de uma universidade federal. Para tanto, fez-se uso de pesquisa documental, observação participante e entrevistas semiestruturadas buscando reunir informações que proporcionassem a elaboração desses objetivos. Por fim, pôde-se perceber que o BSC é um instrumento capaz de auxiliar o departamento em estudo no desenvolvimento de um planejamento estratégico eficiente, proporcionando uma visão sistêmica da organização e a visualização da estratégia por meio das relações de causa-efeito entre os objetivos propostos.

Palavras-chave: BSC; planejamento estratégico; setor público; departamento; universidade.

\begin{abstract}
Currently, a major goal of the organizations is to achieve improvements in organizational performance. At the same time, they are inserted in a context of uncertainty and complexity that demands flexibility in the face of demands and changes in the environment. In this context, the development of a strategic plan that suits the characteristics and aspirations of the organization is essential. The BSC is a methodology that helps in the formulation of planning and setting strategic objectives for organizations, whether private or public sector. Thus, this study seeks to use this methodology to develop proposals for a department goals didactic teaching of a federal university. Therefore, it was made use of documentary research, participant observation and semi-structured interviews seeking to gather information that would provide the development of these goals. Finally, it could be seen that the BSC is a tool to assist the department in a study on the development of efficient strategic planning, providing a systemic view of the organization and visualization of the strategy by the relations of cause and effect between the proposed objectives.
\end{abstract}

Keywords: BSC, strategic planning, public sector department; university. 


\section{INTRODUÇÃO}

Alcançar melhorias no desempenho organizacional configura-se atualmente como um dos principais objetivos das organizações, sejam elas da esfera pública ou do setor privado, dada a importância de se otimizar o uso dos recursos disponíveis e executar da melhor maneira as atividades a que se pretendem.

Ao mesmo tempo, as organizações estão inseridas em um contexto de incertezas, mudanças e complexidade que exige flexibilidade e velocidade de adaptação frente às exigências e às transformações do ambiente. Caso a organização não consiga ter esta dinâmica, ou caso os gestores não tenham informações suficientes para lidar com as situações-problema, corre-se o risco de se perder a atual posição no segmento em que atua e de se acumular perdas sucessivas que comprometem o desempenho institucional.

Diante destes aspectos, a elaboração de um planejamento estratégico adequado às características e pretensões da organização é essencial. O planejamento estratégico, quando bem formulado, proporciona uma visão do futuro que permite à organização potencializar suas forças, minimizar suas fraquezas, além de possibilitar o aproveitamento de oportunidades e a prevenção ante as ameaças que possam surgir.

$\mathrm{Na}$ formulação de um planejamento deve-se estar consciente da influência do ambiente, cada vez mais ágil e complexo, no desempenho da organização e, diante disto, construir cenários que possibilitem fortalecer o posicionamento da instituição no segmento em que atua, possibilitando que ocorra uma efetiva transformação organizacional.

No caso específico das instituições da esfera pública, o planejamento deve estar voltado para a melhoria da performance, que deve ser observada na qualidade do atendimento às demandas sociais, na precisão e transparência das informações, na coerência das ações. Para tanto, é essencial uma ferramenta de mensuração que possibilite a visualização de diversos objetivos, que auxilie na tomada de decisão e, principalmente, que contribua para a elaboração de um plano de ação, capaz de conduzir, com maiores possibilidades de êxito, a organização ao cumprimento do seu objetivo.

O Balanced Scorecard (BSC) é uma metodologia que agrupa uma gama equilibrada de indicadores permitindo aos gestores visualizar a organização sob várias perspectivas ao mesmo tempo, o que possibilita a tradução e a implementação da estratégia. Com esta ferramenta é possível alinhar esforços e objetivos na busca pela melhoria contínua e pela construção de um planejamento eficiente. 
Dentro deste panorama, pode-se questionar: o BSC é uma metodologia capaz de auxiliar na definição de objetivos no processo de elaboração de um planejamento estratégico para um departamento didático-pedagógico de uma instituição federal de ensino superior?

Nesse sentido, o objetivo deste trabalho foi o de formular objetivos para cada uma das perspectivas do Balanced Scorecard, no intuito de contribuir para a construção do planejamento do Departamento de Administração e Economia (DAE) da Universidade Federal de Lavras (UFLA).

Os objetivos específicos englobam: definir a missão, visão e valores do DAE/UFLA; realizar a análise de SWOT do departamento, proporcionando subsídios para a elaboração dos objetivos do BSC e; construir o mapa estratégico, mostrando as relações de causa-efeito entre os objetivos.

\section{BALANCED SCORECARD: CONCEITO, PERSPECTIVAS E MAPA ESTRATÉGICO}

O Balanced Scorecard (BSC) foi criado no início dos anos 1990, a partir de um estudo desenvolvido junto a diversas empresas pelo professor Robert Kaplan, da Universidade de Harvard, e por David Norton, consultor da zona de Boston. Esse estudo tinha por base mostrar que a medição da atuação empresarial focada na contabilidade financeira era uma forma que estava bastante obsoleta e era extremamente limitada para mensurar e gerir os ativos intangíveis (PINTO, 2005).

A sigla BSC significa, em tradução literal, "Indicadores Balanceados de Desempenho", onde o termo balanceado diz respeito à utilização de quatro perspectivas distintas (indicadores financeiros, de clientes, de processos internos e de aprendizado e crescimento), porém muito bem inter-relacionadas entre si.

O primeiro artigo sobre a metodologia do BSC, intitulado "Balanced Scorecard: indicadores que impulsionam o desempenho" foi publicado na Harvard Business Review, em 1992. Foi então apresentado pela primeira vez o termo "Balanced Scorecard" como uma proposta de mensuração estruturada que complementa a abordagem tradicional de avaliação de resultado, integrando os indicadores financeiros com: indicadores representativos dos processos internos; da relação entre empresa e cliente; e da capacidade da organização no que se refere ao aprendizado e crescimento (KAPLAN; NORTON, 1992).

Assim como acontece com o planejamento estratégico, o processo de formulação do Balanced Scorecard também tem início com a definição da missão e da visão da organização, para em seguida, considerando seus valores, avaliar quais seriam as melhores estratégias para 
alcançar os objetivos previstos em cada uma das perspectivas que compõe esta ferramenta. Nesse sentido, Níven (2003) afirma que os quatro pilares básicos que dão consistência para o BSC são: missão, visão, valores e estratégia.

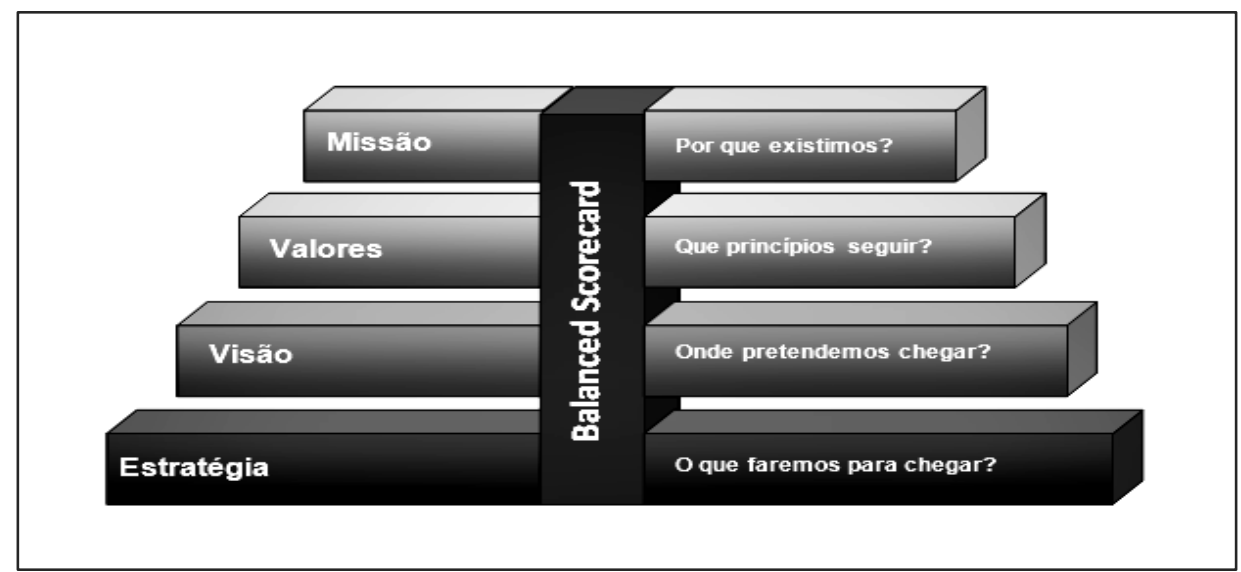

Figura 1 - Matérias-primas do BSC

Fonte: Adaptado de Níven (2003, p. 101).

Portanto, o Balanced Scorecard procura traduzir a visão, a missão e a estratégia da organização em objetivos, indicadores, metas e iniciativas sob a ótica de perspectivas diferentes, que se equivalem a vetores ou dimensões, cuja união, consequentemente, dá forma á metodologia.

Kaplan e Norton (1997) definiram 4 perspectivas básicas para o BSC:

a) Perspectiva Financeira: objetiva evidenciar os resultados financeiros, cujas medidas indicam se a estratégia da empresa, sua implementação e execução, estão contribuindo para melhorar os resultados, ou seja, analisa a lucratividade da estratégia adotada. As medidas e os objetivos neste segmento devem definir a situação financeira que se espera alcançar com o planejamento estratégico, bem como servir de meta principal para as demais perspectivas. As metas financeiras se relacionam com rentabilidade, crescimento e valor para os acionistas. Segundo Kaplan e Norton (1997) duas estratégias são básicas nesta perspectiva: crescimento da receita e produtividade. $\mathrm{O}$ crescimento da receita influencia outras perspectivas no sentido de gerar novas fontes de receita advindas de novos mercados, novos produtos ou novos clientes ou mesmo na ampliação e melhoria com os clientes existentes. Quanto à produtividade há uma influência sobre a execução das atividades operacionais relacionadas aos clientes atuais, incluindo também a redução de custos.

b) Perspectiva dos Clientes: identifica os segmentos de mercado e de clientes em que a organização atua, bem como as medidas de sucesso da empresa nesses segmentos. A continuidade de uma organização depende da sua capacidade para descobrir e satisfazer as necessidades de potenciais clientes e, por este motivo, uma das regras do BSC é identificar os 
fatores que são importantes na conquista de clientes. Estes fatores podem ser divididos em categorias: tempo, qualidade, desempenho e serviço.

c) Perspectiva dos Processos Internos: busca identificar os fatores que atraem, mantêm e valorizam os clientes e, ao mesmo tempo, criar valor aos acionistas. Os processos internos são responsáveis pelas ações implementadas dentro da organização que valorizam as necessidades para o atendimento das diretrizes financeiras e a satisfação dos clientes. O diferencial do BSC é a tentativa de encontrar processos completamente novos em que a instituição deve atingir a excelência, enquanto a maioria dos outros instrumentos de mensuração de desempenho foca nos processos já existentes.

d) Perspectiva do Aprendizado e Crescimento: é o alicerce para o alcance dos objetivos das outras perspectivas. Procura identificar a infraestrutura que a organização necessita para gerar crescimento e melhorias no longo prazo. Determina as potencialidades e a capacidade que a organização precisa ter para elaborar processos internos capazes de gerar valor aos clientes, além de propiciar a disseminação de conhecimentos implícitos e explícitos, no intuito de otimizar a utilização dos recursos.

Prieto et al. (2006) ressaltam que o BSC visto de maneira integrada traduz o conhecimento, as habilidades e sistemas que os funcionários precisarão (seu aprendizado e crescimento) para inovar e construir as capacidades estratégicas certas e eficientes (processos internos) que criarão valor específico aos mercados (clientes), levando provavelmente ao aumento do valor ao acionista (financeiro).

Kaplan e Norton (2004) afirmam que estas quatro perspectivas do BSC têm-se revelado adequadas a diversas organizações, todavia, os autores ressaltam que elas devem ser consideradas como um modelo e não como uma "camisa de força". Não há um teorema matemático em que as quatro perspectivas sejam necessárias e suficientes para todos os tipos de empresas e situações. Embora seja improvável que a metodologia seja aplicada com menos de quatro perspectivas, dependendo das circunstâncias, é possível que seja preciso agregar uma ou mais perspectivas de forma a complementar a realidade da organização.

Para Kaplan e Norton (2004), o mapa estratégico acrescenta uma segunda camada de detalhes ao BSC, na medida em que ilustra a dinâmica temporal da estratégia e também adiciona um nível de detalhe que melhora a clareza e o foco, ao mesmo tempo traduz os objetivos em indicadores e metas.

Cabe destacar que o mapa estratégico de uma organização só será eficaz se ficar claro as relações de causa-efeito entre os objetivos que deverão estar distribuídos entre as diversas perspectivas. O mapa estratégico deve desmembrar a estratégia em temáticas, problemas e 
oportunidades, vinculando uma das perspectivas às áreas e setores operacionais. Assim, a causa em uma dada perspectiva gera efeito em outra, e assim sucessivamente (KAPLAN; NORTON, 1997).

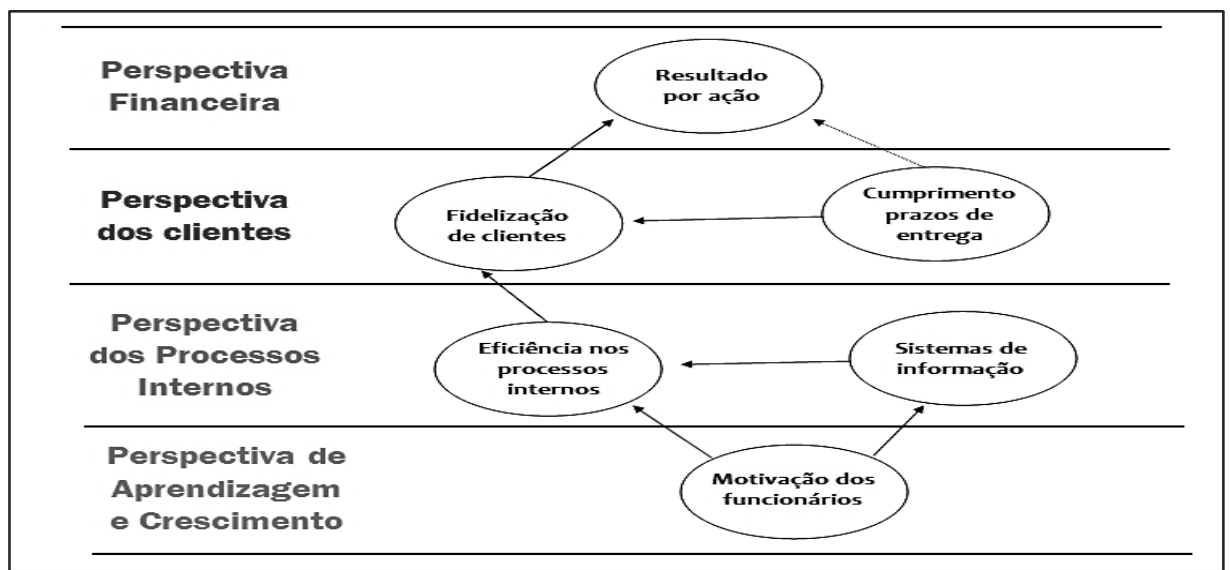

Figura 2 - Exemplo de relações de causa-efeito

Fonte: Adaptado de Ribeiro (2005, p.66).

Para Cesena (2006), definindo-se os indicadores a partir dos objetivos estratégicos e de suas relações, reforça-se o vínculo com a estratégia, e consequentemente com o planejamento estratégico, uma vez que promove a coerência com as hipóteses delineadas e com a capacidade de aprofundar (por meio do indicador) a descrição do processo de criação de valor.

\section{O BSC NO SETOR PÚBLICO}

A Administração Pública, assim como as organizações sem fins lucrativos, estão constantemente diante de responsabilidades e exigências complexas e de desafios cada vez maiores, os quais são basicamente decorrentes das metas e dos objetivos a serem alcançados, por vezes conflitantes: por exemplo, aumentar o número e a qualidade dos serviços prestados e, concomitantemente, aumentar a eficiência. Estas organizações enfrentam a necessidade latente de desenvolver mecanismos e modelos eficazes para medir, avaliar e gerir o seu desempenho (PINTO, 2005; GHELMAN; COSTA, 2006b).

Diante deste cenário, as organizações do setor público não estiveram alheias ao sucesso dos resultados obtidos com a implementação do Balanced Scorecard, apesar desta ferramenta ter sido criada e desenvolvida para aplicação nas empresas do setor privado, como mencionado anteriormente. Defronte com as necessidades de modernizar a gestão e implantar um planejamento estratégico eficiente, a Administração Pública percebeu rapidamente que o BSC continuava a figurar-se como poderoso instrumento de gestão para comunicar, 
implementar e avaliar a execução da estratégia em segmentos além da fronteira do setor privado (PINTO, 2004).

Para Kaplan e Norton (2000), a utilização do BSC em organizações públicas se difunde com a experiência da cidade norte-americana de Charlotte, na Carolina do Norte, no início da década de 1990, a qual passa a seguir uma estratégia de criação de valor ao "cidadão-cliente". A partir de então, a adoção do Balanced Scorecard vem crescendo constantemente como uma forma de se estabelecer foco, prioridade, racionalização e eficiência dos programas estratégicos de governo. Assim, o BSC firma-se como um modelo de gestão útil para a realidade pública, particularmente, por conseguir estabelecer uma ligação entre a declaração da missão e da estratégia e as medidas de desempenho da operacionalização da organização.

O BSC também contribui com uma mudança de foco da coordenação de programas e projetos para os resultados que se pretende alcançar a partir destas ações. Desta forma, possibilita-se o alinhamento das iniciativas da organização, de departamentos e dos indivíduos de forma a reforçar a performance uns dos outros, e, por consequência, conquistar um desempenho conjunto bem melhor.

No BSC original, voltado para as empresas privadas, todo o desempenho é norteado por um objetivo final: aumento de valor para os investidores, por meio da obtenção de resultados financeiros crescentes, em outras palavras, a maximização do lucro. Por esta razão, a perspectiva financeira é colocada no topo do Balanced Scorecard, servindo de fio condutor às outras três perspectivas (PINTO, 2004). Todavia, para Vidi (2009) e Ghelman e Costa (2006b), esta estrutura original do BSC não se adéqua aos propósitos de uma organização pública, pois o sucesso financeiro não é considerado como o principal objetivo organizacional. O foco são os clientes das instituições ou a própria sociedade em si, que ocupam, portanto, o topo da hierarquia no Balanced Scorecard.

Pinto (2004) ressalta que o BSC adaptado às organizações do setor público coloca importante ênfase na missão, que passa a status de elemento essencial. Segundo o mesmo autor, muito embora os serviços públicos tenham que gerir eficientemente os recursos, este não se configura como seu principal objetivo.

Ao mesmo passo, Ghelman e Costa (2006a) ressaltam que o Balanced Scorecard na esfera pública também deve considerar ações direcionadas a garantir efetividade, eficácia e eficiência, uma vez que qualquer organização pública, para prestar serviços com excelência, precisa realizar a sua função social (efetividade) com qualidade na prestação de serviços (eficácia) e com o menor consumo de recursos possível (eficiência). Para estes autores, uma 
instituição pública que pretenda apenas ser mais eficiente, reduzindo custos e aumentando a sua produtividade, pode comprometer a qualidade da prestação do produto/serviço ofertado. Da mesma forma que ofertar um produto e/ou serviço com eficiência e eficácia não é garantia de alcançar a efetividade, que se configuraria na geração de benefícios, efeitos ou impactos diretos ou indiretos no cumprimento da função organizacional.

Neste contexto, Ghelman e Costa (2006a) desenvolveram um modelo adaptado do BSC para aplicação em organizações do setor público, o qual compreende três perspectivas do modelo original de Kaplan e Norton - Clientes, Processos Internos e Financeira -, duas novas perspectivas oriundas da divisão da perspectiva Aprendizagem Crescimento - Pessoas e Modernização Administrativa -, além de incluir outra perspectiva - Sociedade/Cidadão - com o objetivo de mensurar a efetividade das ações públicas. Para os autores, este modelo contempla a Perspectiva Financeira como estando diretamente relacionada aos recursos e orçamento que as instituições públicas dispõem para arcar com suas despesas. As Perspectivas das Pessoas, da Modernização Administrativa e dos Processos Internos estão relacionadas com o aspecto de eficiência, visto que processos internos eficientes, uma equipe de funcionários bem treinada e motivada e um modelo de gestão moderno e bem estruturado contribuirão para uma organização mais eficiente. A Perspectiva dos Clientes remete ao cliente direto da organização pública (no caso de uma instituição de ensino, os alunos) e alcançando a satisfação destes clientes, estaria, por consequência, sendo eficaz. Por fim, a Perspectiva Sociedade/Cidadão seria aquela que mensuraria a efetividade da organização, bem como os impactos e reflexos de sua atuação.

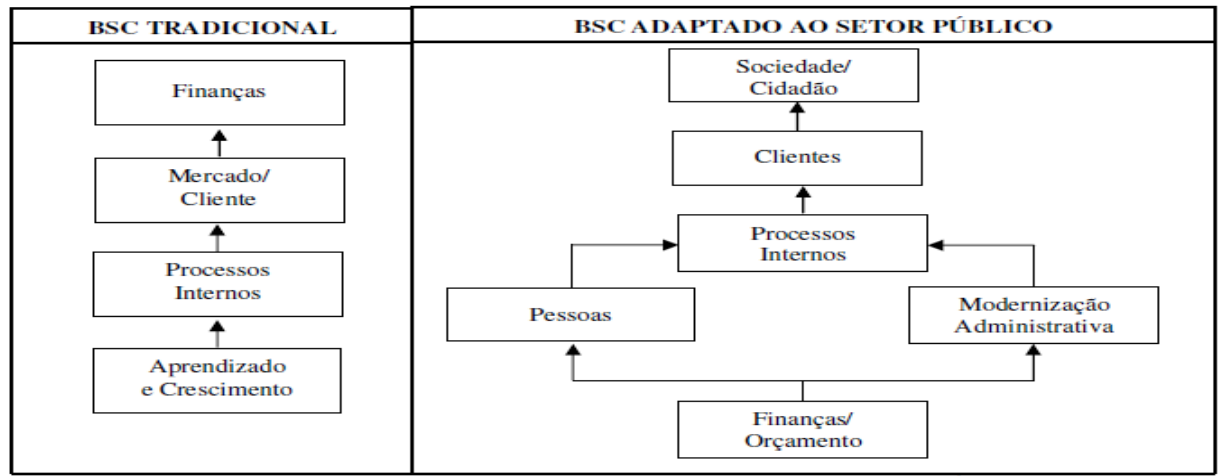

Figura 3 - Diferenças entre o BSC Tradicional e o adaptado ao setor público Fonte: Ghelman e Costa (2006a, p. 8).

$\mathrm{Na}$ proposta de Balanced Scorecard adaptado as dimensões de desempenho de eficiência, eficácia e efetividade para a esfera pública de Ghelman e Costa (2006a), um bom andamento da perspectiva financeira impacta positivamente na perspectiva pessoas e na perspectiva de modernização administrativa. Estas duas perspectivas, por sua vez, conduzem 
a uma melhoria nos processos internos. Estas perspectivas (pessoas, modernização administrativa e processos internos) têm uma relação direta com a perspectiva cliente, pois uma organização que possui um quadro de funcionários capacitado e motivado busca permanentemente melhorar a sua gestão interna, tem processos eficientes e clientes satisfeitos.

Portanto, independente das adaptações que foram feitas no modelo original do BSC para utilizá-lo no setor público, após a definição das perspectivas o passo seguinte é reconfigurar os objetivos estratégicos e as metas, para que possam ser definidas as relações causa-efeito entre eles e seus indicadores.

\section{PROCEDIMENTOS METODOLÓGICOS}

O presente estudo pode ser classificado como aplicado e de cunho qualitativo. A pesquisa é aplicada, uma vez que tem como finalidade a resolução de problemas concretos ao utilizar uma adaptação da ferramenta de gestão estratégica conhecida como Balanced Scorecard à realidade da gestão em um segmento (departamento didático-pedagógico) de uma instituição pública de ensino superior. Para isso, são analisadas como a metodologia do BSC se enquadra na esfera pública e é apresentada uma proposta de objetivos para serem utilizados na elaboração de um planejamento estratégico para o Departamento de Administração e Economia da UFLA.

Nesta perspectiva, para Vergara (2000), a pesquisa aplicada é motivada pela necessidade de resolver problemas concretos, mais imediatos, ou não. Em outras palavras, o estudo aplicado tem finalidade prática, ao contrário da pesquisa pura, motivada basicamente pela curiosidade intelectual do pesquisador e situada, sobretudo no nível da especulação.

A pesquisa de cunho qualitativo trabalha os dados buscando seu significado, tendo como base a percepção do fenômeno dentro do seu contexto. Para Gil (1999), o uso desse tipo de pesquisa permite o aprofundamento da investigação em questões relacionadas ao objeto de estudo e suas relações, mediante máxima valorização do contato direto com a situação estudada. Busca-se o que é comum, mantendo-se, contudo, aberto para perceber a individualidade e os significados múltiplos.

O método da pesquisa é o estudo de caso. Para Triviños (1995), o aprofundamento do estudo qualitativo, de forma exaustiva, de um ou de poucos objetos, restrito a uma determinada unidade, possibilitando um conhecimento detalhado sobre o assunto, pode ser caracterizado como estudo de caso. Este método admite a utilização de diversas técnicas de coleta de informações, a verificação de diferentes dimensões e abrangências de um objeto e a utilização de dados tanto quantitativos quanto qualitativos. 
$\mathrm{Na}$ tentativa de coletar informações que possam ser complementares no sentido de oferecer maior coerência ao resultado final desse estudo, optou-se por recorrer a várias fontes de evidências. A utilização de fontes diversas na coleta de dados é uma necessidade e, ao mesmo tempo, um ponto forte muito importante para os estudos de caso.

Utilizou-se da pesquisa documental para o levantamento de dados secundários de diversas fontes documentais disponibilizadas pela Universidade Federal de Lavras e pelo Departamento de Administração e Economia (DAE/UFLA), na tentativa de fazer uma reconstituição histórica de ambos, analisando com maior profundidade os documentos referentes ao plano de desenvolvimento institucional da universidade, sobre criação e o desenvolvimento do departamento, bem como sua estrutura organizacional, dentre outros.

Foram coletados dados primários por meio de entrevistas realizadas utilizando questionários semiestruturados, sendo estes de três espécies: a) para professores e servidores técnico-administrativos do departamento; b) para alunos e ex-alunos do departamento e; c) para servidores de cargos administrativos e de direção na universidade.

A amostra escolhida para a realização das entrevistas foi a não probabilística por conveniência. A escolha desse tipo de amostragem teve como intuito a tentativa de abranger os requisitos mínimos na escolha de um bom informante que, conforme Triviños (1995) seriam: ter vivenciado, desde o princípio, o fenômeno que se deseja estudar e ter conhecimento amplo das situações que envolvem e/ou influenciam o objeto em estudo, além de saber expressar com detalhes aspectos essenciais sobre o fenômeno ora estudado. Dessa forma, era importante ouvir realmente quem vivencia a rotina do departamento, utiliza e oferece os serviços e, portanto tem um alto nível de conhecimento das questões que envolvem o DAE.

Para este estudo, foi definida uma amostra não-probabilística de vinte e nove entrevistados, sendo 13 servidores do departamento, 09 alunos e ex-alunos de cursos gerenciados pelo departamento e 07 administradores, superintendentes e pró-reitores de outros setores da universidade.

No segmento formado por servidores do Departamento de Administração e Economia, adotaram-se como critérios para seleção de entrevistados: i) o tempo em que o funcionário trabalha na organização, ou seja, aqueles servidores que trabalham há mais tempo no DAE; e ii) a função que o servidor exerce na estrutura organizacional do departamento. Desta forma, dentro do primeiro critério, foram entrevistados 03 técnico-administrativos, um coordenador de curso de graduação, um coordenador de curso de pós-graduação e um membro da Câmara de Infraestrutura do departamento. Pelo segundo critério, foram entrevistados os presidentes 
das câmaras de Ensino, de Pesquisa, de Extensão, de Finanças, os presidentes das comissões de Assuntos Estratégicos e de Assuntos Internacionais, além do chefe do departamento. Em suma, as duas categorias são compostas por funcionários que tendem a ter maiores condições de fornecer informações importantes sobre a realidade do departamento e que exercem algum tipo de representatividade sobre os demais servidores.

No segmento formado por alunos e ex-alunos, foram entrevistados 03 alunos de graduação ou pós-graduação que participam de algum núcleo de estudo, grupo de pesquisa, empresa júnior, programa de monitoria, etc. do departamento; 03 alunos de cursos de graduação ou de pós-graduação que não fazem parte de nenhuma das atividades listadas anteriormente e; 03 ex-alunos de graduação/pós-graduação que se formaram há no máximo três anos. Esta divisão buscou dar maior diversidade a este segmento de entrevistados, uma vez que foram obtidas informações de discentes que participam ativamente do departamento, de outros que não tem uma relação tão direta com as atividades cotidianas do departamento e também aqueles que já não possuem mais vínculo com a instituição, mas que usufruíram de sua estrutura e de seus serviços.

Por fim, na fatia da amostra composta por superintendentes, pró-reitores e administradores de setores e de outros departamentos da universidade, foram convidados para a entrevista um superintendente da Pró-Reitoria de Planejamento e Gestão (PROPLAG), os pró-reitores de Graduação, de Pós-Graduação, de Pesquisa e de Extensão, além dos administradores do Departamento de Biologia e do Departamento de Medicina Veterinária. O superintendente da PROPLAG foi selecionado por trabalhar diretamente com todas as questões relacionadas ao planejamento da universidade. Os pró-reitores selecionados são aqueles cujas pró-reitorias remetem às atividades fins da universidade e, por conseguinte, do departamento: ensino, pesquisa e extensão. Os administradores escolhidos fazem parte do grupo inicial do projeto desenvolvido pela PROPLAG de alocação de administradores em departamentos didático-pedagógicos e pró-reitorias da universidade. As percepções apresentadas pelos administradores, superintendentes e pró-reitores são de grande contribuição para a compreensão da imagem e do papel que o DAE exerce dentro da universidade.

Com a utilização da pesquisa documental, observação participante e a opção por questionários semiestruturados pretendeu-se desenvolver linhas convergentes de investigação, com o intuito de obter máxima amplitude na coleta de informações gerenciais sobre o Departamento de Administração e Economia e, desta forma, elaborar as propostas de objetivos para o planejamento estratégico. 
A técnica de análise de dados adotada foi a análise de conteúdo, segundo a qual é possível enriquecer a leitura e ultrapassar as incertezas, extraindo conteúdos por trás da mensagem analisada. Para Laville e Dione (1999), por meio deste tipo de análise é possível desmontar a estrutura e os elementos do conteúdo, na tentativa de esclarecer suas diferentes características e significação. A análise de conteúdo contempla as etapas de explicitação, sistematização e expressão dos conteúdos em estudo, para possibilitar a construção de deduções lógicas e justificadas a respeito dos indivíduos que produziram as mensagens, o contexto e os efeitos advindos delas. Dentro deste contexto, as informações coletadas através das entrevistas foram utilizadas para a análise SWOT do departamento e para fornecer os dados necessários para a elaboração do Balanced Scorecard e para a formulação da proposta de planejamento estratégico.

As três variações de questionários utilizados (para professores e servidores do departamento; para alunos e ex-alunos; para gestores e superintendentes da universidade) possuem questões que permitiram identificar, segundo a opinião dos entrevistados, os pontos fortes e fracos, ameaças e oportunidades para o Departamento de Administração e Economia. Estes três tipos de questionários também continham perguntas voltadas à identificação de metas e indicadores de desempenho capazes de mensurar a performance do departamento, bem como à determinação de iniciativas que possam ser realizadas dentro de cada uma das perspectivas do Balanced Scorecard, conforme apresentados a seguir.

\section{Questionário Tipo 01: Servidor /Professor}

1) Na sua opinião, qual é a "MISSÃO", ou seja, qual a razão da existência (finalidade) do Departamento de Administração e Economia (DAE)?

2) Na sua opinião, qual é a "VISÃO" do DAE, ou seja, o que o departamento pretende realizar ou onde pretende chegar daqui alguns anos?

3) Quais são os valores (princípios, regras morais) que acredita nortearem as ações do DAE?

4) Cite pelo menos dois diferenciais (qualidades, pontos positivos) que você acredita que o DAE possui.

5) Cite pelo menos dois aspectos negativos que você julga que precisam ser melhorados, modificados ou mesmo suprimidos no DAE.

6) Tendo em vista o contexto da atual gestão da universidade e a forma como o atual governo desenvolve políticas e ações voltadas ao ensino superior, que fatores você considera como oportunidades que possam ser aproveitadas pelo departamento para crescer, se desenvolver?

7) Dentro da mesma perspectiva da questão anterior, quais seriam as ameaças que o departamento está sujeito considerando as práticas do governo federal e também da gestão da universidade?

8) Você acredita que os recursos do DAE são bem administrados?

- Se sim, quais ações você sugeriria para melhorar ainda mais a administração deste orçamento?

- Se não, o que você julga estar sendo feito de forma equivocada? O que sugere para corrigir estas distorções?

9) Você enxerga alguma(s) forma(s) de ampliar a capacidade financeira do departamento? Como?

10) Como você avalia a relação interpessoal e a convivência com os demais funcionários do departamento?

11) Que ações você acredita que deveriam ser realizadas para melhorar o ambiente organizacional? E quais seriam importantes para valorizar e motivar os funcionários?

12) Como você vê a gestão do departamento? Onde enxerga que possam ocorrer melhorias?

13) Você possui autonomia para realizar suas atividades e tomar decisões relacionadas à execução do seu trabalho? - Se sim, qual o reflexo disso no desempenho da sua função?

- Se não, como essa falta de autonomia prejudica seu desempenho?

14) Você acredita que seja necessário algum treinamento ou capacitação para realizar ou aprimorar suas 
atividades? Qual (is) e por quê?

15) Você julga que possui os equipamentos e softwares necessários para executar bem seu trabalho? Se não, o que acredita que esteja faltando?

16) E os demais funcionários, você acredita que possuam o necessário para desempenhar suas atividades? O que julga ser preciso melhorar?

17) Onde você acredita que o departamento possa melhorar para agilizar e dinamizar a execução das tarefas cotidianas dos funcionários, no intuito de prestar um melhor serviço aos discentes, ao restante da comunidade universitária e também à sociedade?

18) Como você avalia o atendimento proporcionado pelas secretarias, centro de documentação e administração geral aos discentes? $O$ que você acredita que possa ser realizado pelo departamento para aperfeiçoar este atendimento?

19) Como você avalia o atendimento aos discentes pelo departamento no que se refere à formação acadêmica, projetos de pesquisa e de extensão, núcleos de estudo, etc. ? O que julga que possa ser melhorado?

20) Como você percebe os reflexos do serviço prestado pelo departamento (formação acadêmica) na sociedade de forma geral? Quais aspectos você acredita que possam ser trabalhados pelo departamento para aperfeiçoar este serviço de forma a favorecer ainda mais a sociedade?

Fonte: Elaboração dos autores, 2013.

\section{Questionário Tipo 02: Alunos / Ex-Alunos do DAE.}

1) Na sua opinião, qual é a "MISSÃO", ou seja, qual a razão da existência (finalidade) do Departamento de Administração e Economia (DAE)?

2) Na sua opinião, qual é a "VISÃ̃" do DAE, ou seja, o que o departamento pretende realizar ou onde pretende chegar daqui alguns anos?

3) Quais são os valores (princípios, regras morais) que acredita nortearem as ações do DAE?

4) Cite pelo menos dois diferenciais (qualidades, pontos positivos) que você acredita que o DAE possui.

5) Cite pelo menos dois aspectos negativos que você julga que precisam ser melhorados, modificados ou mesmo suprimidos no DAE.

6) Tendo em vista o contexto da atual gestão da universidade e a forma como o atual governo desenvolve políticas e ações voltadas ao ensino superior, que fatores você considera como oportunidades que possam ser aproveitadas pelo departamento para crescer, se desenvolver?

7) Dentro da mesma perspectiva da questão anterior, quais seriam as ameaças que o departamento está sujeito considerando as práticas do governo federal e também da gestão da universidade?

8) Como você avalia o atendimento prestado pelos funcionários do DAE nas secretarias, centro de documentação, administração geral, etc.? $O$ que acredita que possa ser melhorado?

9) Na sua opinião, qual a situação do departamento no que se refere à disposição de equipamentos e materiais necessários para a boa execução de suas atividades? O que sugere como melhorias?

10) Como você avalia a gestão do departamento? Quais são os aspectos positivos? E quais o negativos?

11) Qual a sua percepção sobre a qualidade do serviço prestado pelo departamento no que se refere às disciplinas ofertadas, possibilidades de projetos de extensão e de pesquisa, à condução dos cursos de graduação ou de pósgraduação, etc.? O que acredita que possa ser melhorado?

12) Defina em poucas palavras qual a sua opinião sobre o DAE, no que tange ao ambiente do departamento, à sua relação com os funcionários e com os professores, ao atendimento que o departamento presta ao público, à imagem do departamento perante à universidade e à sociedade, etc.

Fonte: Elaboração dos autores, 2013.

\section{Questionário Tipo 03: Administradores, superintendentes e pró-reitores.}

1) Comparado a outros departamentos e setores da universidade, cite pelo menos dois diferenciais (qualidades, pontos positivos) que você acredita que o DAE possui.

2) Comparado também a outros departamentos e setores da universidade, cite pelo menos dois aspectos negativos que você julga que precisam ser melhorados, modificados ou mesmo suprimidos no DAE.

3) Tendo em vista o contexto da atual gestão da universidade e a forma como o atual governo desenvolve políticas e ações voltadas ao ensino superior, que fatores você considera como oportunidades que possam ser aproveitadas pelo departamento para crescer, se desenvolver?

4) Dentro da mesma perspectiva da questão anterior, quais seriam as ameaças que o departamento está sujeito considerando as práticas do governo federal e também da gestão da universidade?

5) Na sua opinião, qual a imagem do DAE perante à comunidade acadêmica e à sociedade, em geral ? O que pode ser feito para melhorar ou reforçar essa imagem?

6) Qual a sua percepção sobre a forma como o DAE é administrado? Quais os pontos positivos e quais os aspectos que precisam ser trabalhados?

Fonte: Elaboração dos autores, 2013 
A escolha pela análise de conteúdo se fez importante por permitir identificar resultados com propriedades bem definidas e padrões de ocorrência efetivamente encontrados nos depoimentos. O foco era destacar das entrevistas os conteúdos mais frequentes, o que de fato apresentava um alto nível de ocorrência. Isso se justifica à medida que para construir um planejamento baseado no BSC torna-se necessário evidenciar as prioridades, o que o grupo entrevistado destacou e, portanto, se caracterizou como um ponto efetivamente encontrado.

Destarte, é importante destacar que, para o desenvolvimento deste estudo, foi adotado o modelo de Balanced Scorecard desenvolvido por Ghelman e Costa (2006a), especialmente adaptado para organizações da esfera pública.

\section{ESTUDO DE CASO}

Este estudo de caso inclui quatro etapas essenciais. A primeira é uma breve apresentação de um perfil organizacional do Departamento de Administração e Economia e a definição da missão, da visão e dos valores do DAE/UFLA. Em seguida, é realizada a análise de SWOT do departamento. A terceira etapa corresponde à formulação de objetivos para cada uma das perspectivas do BSC. A quarta e última etapa é a construção do mapa estratégico, com a relação de causalidade entre os objetivos estratégicos propostos.

\subsection{Perfil organizacional e Missão, visão e valores do DAE/UFLA}

O Departamento de Administração e Economia (DAE) esteve presente na história da Universidade Federal de Lavras desde os primeiros momentos em que começou a se configurar uma estrutura departamental, ainda na Escola Superior de Agricultura de Lavras (ESAL). No início da década de 1970, com a evolução da estrutura de departamentos, foi criado o Departamento de Ciências Sociais que, no ano de 1973, passou a denominar-se Departamento de Economia Rural, contando apenas com cinco professores. Desde o princípio, o foco das atividades era voltado para o ensino, a pesquisa e a extensão, tendo desenvolvido importante papel na difusão de métodos e técnicas de contabilidade, economia e administração rural.

O DAE, hoje, está estruturado em três prédios (Blocos I, II e III) e mantém os cursos presenciais de graduação em Administração (integral) e em Administração Pública (noturno), graduação à distância em Administração Pública, mestrado e doutorado acadêmicos em Administração e mestrado profissional em Administração Pública.

O corpo docente do departamento é composto por 31 professores doutores e 11 mestres, dos quais 09 são doutorandos, além de 04 professores com pós-doutorado concluído 
e um ainda em curso. O quadro técnico-administrativo é formado por seis servidores concursados e dois terceirizados e ainda conta com o apoio de 03 funcionárias responsáveis pela limpeza e serviços gerais.

No que se refere à organização e ao funcionamento, no DAE a administração é exercida pela Chefia do Departamento e pela Assembleia Departamental. Ao contrário dos demais departamentos didático-pedagógicos da Universidade Federal de Lavras, no Departamento de Administração e Economia a estrutura administrativa também é composta por Câmaras Permanentes, por Comissões e por um Conselho Consultivo que auxiliam na gestão e funcionamento do departamento. São sete Câmaras Permanentes (de Ensino, de Pesquisa, de Extensão, de Seleção e Treinamento, de Finanças, de Informática e de Infraestrutura), duas Comissões (de Assuntos Estratégicos e de Assuntos Internacionais) e uma Subcomissão Setorial (de Avaliação de Documentos), todas compostas por docentes e técnico-administrativos lotados no DAE, que têm como objetivo principal subsidiar a gestão do departamento em suas áreas de competência.

No entanto, apesar da estrutura organizacional diferenciada e de se tratar de um departamento de Administração, o DAE não mantém em sua gestão a cultura do planejamento. Salvo algumas iniciativas pontuais, o departamento carece de medidas mais efetivas no que se refere à incorporação do planejamento em seus procedimentos administrativos.

O Departamento de Administração e Economia, apesar de ser o berço do estudo em ciências sociais aplicadas na Universidade Federal de Lavras, não possui claramente estabelecida a sua missão, sua visão e os valores que regem e norteiam ações de seus funcionários, gestores e colaboradores. Considerando que é a definição destes três fatores o primeiro passo no processo de formulação de um planejamento estratégico bem fundamentado, conforme assegura Níven (2003), buscou-se, então, delinear quais seriam a missão, a visão e os valores do DAE a partir da percepção dos alunos e dos servidores e professores lotados no departamento.

Quando perguntados sobre a missão do DAE, por meio da análise das respostas de cada entrevistado, foi possível perceber três pilares básicos e comuns: ensino, pesquisa e extensão. A seguir, o depoimento de dois entrevistados demonstram isso:

“A missão do DAE, como de todos os departamentos da universidade, é a de garantir uma realização de qualidade das funções da universidade, quais sejam ensino, pesquisa e extensão. Então, o DAE tem que se estruturar do ponto de vista humano, de equipamentos, etc., para garantir o pleno cumprimento destas funções”( Entrevistado 9) 
“[...] Eu penso que a missão do DAE é a de contribuir para o avanço do conhecimento em Administração, buscando capacitar seus discentes com discernimento e habilidade para pesquisar, ensinar, empreender, gerenciar e conduzir mudanças por meio da sua atuação profissional, seja na área gerencial ou em atividades de docência, extensão ou pesquisa, e consequentemente formar administradores com alta competência e socialmente responsáveis, que por sua vez contribuirão para a melhoria de nossa sociedade" (Entrevistado 22).

Nesse sentido, diante das respostas que obtiveram uma ocorrência significativa e levando-se em conta que a missão do departamento deve estar alinhada com os objetivos da universidade, é possível sintetizá-la da seguinte forma: A missão do DAE é contribuir para o desenvolvimento e promoção da excelência do ensino, pesquisa e extensão na área de ciências sociais aplicadas, formando profissionais capacitados em Administração, cientes do seu papel na sociedade, seja no âmbito acadêmico, no mercado ou no setor público, com ética e comprometimento.

A visão remete ao estado ou situação em que o DAE pretende estar daqui a determinado período de tempo ou, mais precisamente, onde deseja chegar. Ela é um desdobramento da missão da organização, ou seja, um elemento está diretamente relacionado ao outro. Esta relação pôde ser percebida por meio da análise das entrevistas realizadas com discentes e servidores/professores do departamento em estudo. Ao serem interrogados sobre a visão do DAE, todas as respostas apresentaram elementos associados ao que havia sido apontado, anteriormente, quando questionados sobre a missão. No conjunto das observações colhidas observou-se frequência em pontos como: aperfeiçoamento na forma como o ensino é oferecido, aproximar teoria e prática no processo de aprendizagem, aproximar o departamento da sociedade, promovendo resultados mais práticos, ser mais atuante na sociedade, melhorar o processo de formação dos alunos e incentivar a pesquisa e a extensão da área de Administração.

A importância de trabalhar para estar entre os melhores cursos de graduação e pósgraduação do país, alcançando conceitos mais altos e melhores avaliações, configura-se como um elemento que deve estar presente na visão do DAE, sendo apontado pelos entrevistados.

Por outro lado, os entrevistados destacaram o fato do departamento não ter uma visão bem definida, colocando esta situação como um dificultador quando se pretende traçar qualquer plano ou ação estratégica. A seguir, estão apresentadas as opiniões relatadas durantes as entrevistas:

“Eu não vejo uma visão estabelecida, não. Pelo menos não definida de forma oficial [...]. Fazemos parte de uma instituição federal, tudo está atrelado ao sistema do serviço público. Então devemos nos adequar à realidade da gestão pública, onde a cada quatro anos, tudo pode mudar e esta visão pode acabar se alterando. No entanto, pelo tempo que trabalho aqui, não consigo identificar esta visão bem definida” (Entrevistado 1). 
"Eu não consigo enxergar, com muita clareza, perspectiva de médio e longo prazo, nem no departamento, nem na universidade. Eu percebo que o movimento é de cumprir aquilo que o MEC estabelece ou que a Reitoria estabelece como prioritário [...], ou seja, eu não consigo perceber, a médio e longo prazo, alguma proposta que esteja sendo construída pelo departamento, ou mesmo pela universidade” (Entrevistado 9) .

“A visão do departamento, realmente, eu acredito que haveria a necessidade de estruturá-la [...], pois ela tem a ver com uma perspectiva de futuro: onde efetivamente o departamento pretende chegar? Nesse sentido, falta ao departamento reunir um grupo de professores, envolvendo também os demais servidores e representantes dos discentes para discutir e delinear esta visão" (Entrevistado 10).

Estas críticas, no entanto, podem ser explicadas pela própria natureza do departamento. O DAE, assim como a universidade da qual faz parte, está suscetível às particularidades inerentes às organizações do setor público, tais como a mudança periódica de gestão, a legislação específica, a centralização de decisões relacionadas a políticas públicas apenas em nível nacional, desconsiderando os aspectos locais, etc. Estes elementos dificultam o processo de construção de uma visão organizacional, na medida em que contribuem para que ocorra uma descontinuidade nas ações e programas desenvolvidos, mudanças prematuras de metas, carência de medidas que vislumbrem resultados em longo prazo, dentre outros.

Neste contexto, o planejamento estratégico tem papel importante, na medida em que possibilita à organização realizar uma autoavaliação e estabelecer, de forma clara, onde ambiciona chegar e o que pretende realizar em um determinado período de tempo.

Diante do exposto, percebe-se que a visão de uma organização deve ser inspiradora e incentivar seus colaboradores, ao mesmo passo, deve conter metas para que seja algo concreto e passível de ser alcançado. Em suma, a visão deve conter tanto a ideologia e o porquê da existência do departamento, quanto o que se pretende alcançar e criar no futuro. Considerando esta premissa e todos os aspectos mencionados nas entrevistas, a visão do Departamento de Administração e Economia pode ser assim definida: Ser referência nacional e internacional em ensino, pesquisa e extensão na área de ciências sociais aplicadas e aproximar cada vez mais da sociedade os benefícios e conhecimentos gerados pelo departamento.

Por fim, o último passo desta primeira etapa na construção da proposta de planejamento é a definição dos valores que estão presentes no ambiente organizacional do DAE, bem como nas relações entre docentes, alunos e funcionários e destes com os demais membros da comunidade acadêmica e da sociedade. Os valores são princípios ou crenças que funcionam como guia para os comportamentos, atitudes e decisões.

Por meio da análise de conteúdo do material coletado nas entrevistas, percebe-se, tanto por parte dos docentes, quanto dos servidores técnico-administrativos e dos alunos, uma proximidade entre as respostas quando interrogados sobre quais seriam os valores que 
norteiam as ações do Departamento de Administração e Economia da UFLA. Esta percepção fica evidente nos trechos das entrevistas, a seguir:

"Nas pessoas com as quais tenho mais contato, com as quais convivo aqui no DAE, eu percebo que há muita ética, responsabilidade, honestidade. Mas quero deixar claro que isso, eu falo sobre as pessoas com as quais eu convivo diariamente, com as quais tenho mais contato" (Entrevistado 3 ).

"Valores que identifico são os princípios éticos, honestidade, respeito a todos os profissionais que trabalham aqui, valorização das pessoas [...]. Comprometimento com o ensino, com a pesquisa e com a extensão" (Entrevistado 11).

Os valores que podemos observar aqui no DAE, tanto entre servidores, professores, alunos bolsistas e os próprios alunos envolvidos nas entidades, tais como PET, empresa júnior, o CIM, são o respeito mútuo entre as pessoas, a honestidade [...], a transparência, pois tudo aquilo que se vai fazer, geralmente, se procura discutir com o [...] responsável imediato. Outros valores extremamente importantes, a ética e também a responsabilidade. (Entrevistado 10$)$

Considerando a importância e o fato de que estes princípios devem ser perenes, podem-se elencar, com base no conteúdo das entrevistas, os seguintes valores para o DAE/UFLA: "Ética; respeito às pessoas; honestidade; transparência; compromisso com a qualidade; comprometimento com a sociedade; profissionalismo; trabalho em equipe; comprometimento com o ensino, pesquisa e extensão”.

\subsection{Análise de SWOT do DAE/UFLA}

Por ser uma ferramenta utilizada para fazer análise de cenários e a verificação de ambientes, dentro e fora da organização, a análise de SWOT se configura, segundo Weihrich (1982) e Silveira (2001), como importante fonte de informações para gestão e como base fundamental para a formulação de um plano estratégico.

Para a realização da análise de SWOT, o questionário apresentou questões que abordavam a percepção dos entrevistados quanto aos pontos fortes e fracos do DAE e quanto às ameaças e oportunidades às quais o departamento estaria sujeito, considerando as atuais políticas do governo federal e as decisões tomadas pela atual administração central da universidade. Estas questões foram comuns aos questionários dos três grupos de entrevistados (docentes e técnico-administrativos; alunos e ex-alunos; e pró-reitores e outros gestores da UFLA), pois o intuito era conseguir traçar um panorama geral do DAE, englobando todos os ângulos, ou seja, sob o ponto de vista de quem trabalha no departamento, de quem estuda e faz uso dos serviços prestados por ele e também do ponto de vista daqueles que estão de fora do departamento, mas que têm ou que tiveram alguma relação com ele. 
Devido à diversidade dos entrevistados, vários elementos foram levantados sobre as forças, fraquezas, ameaças e oportunidades relacionadas ao DAE. No entanto, muitas das respostas apresentaram aspectos convergentes, que permitiram validar quais seriam os elementos de maior relevância para o estudo e que possibilitariam a construção de um diagnóstico mais próximo do contexto real. A análise de conteúdo permitiu identificar os depoimentos mais frequentes nas entrevistas. Assim foi evidenciada as forças, fraquezas, oportunidades e ameaças mais relevantes.

Trechos das entrevistas retratam esta percepção:

“A qualificação profissional dos docentes do DAE é com certeza um ponto positivo. Ali há professores de vários segmentos, com várias formações acadêmicas. Essa pluralidade se reflete também em projetos, em linhas de pesquisa, na própria extensão [...]. A organização financeira também é muito interessante, porque lá tem inclusive aquele professor de Contabilidade que dá um suporte nessa área [...]. A gente nota como as coisas lá são bem organizadas, o pessoal trabalha em conjunto" (Entrevistado 25).

"É preciso se aproximar mais do mercado. Eu sei que é difícil fazer isto, dada a dificuldade da relação entre o público e o privado, o fato da universidade ser uma autarquia e tem todas as questões legais [...], mas é necessário pensarmos de que maneira podemos fazer essa aproximação." (Entrevistado 13).

"O parque tecnológico da UFLA já é uma realidade [...]. A UFLA está crescendo por uma vertente onde o Departamento de Administração e Economia irá ter um papel muito importante [...] na geração de tecnologia e na disseminação da cultura do empreendedorismo na universidade" (Entrevistado 29).

"Esta frente que será aberta com o parque tecnológico e essa política do governo de incentivo à inovação são oportunidades que o departamento tem que entrar de cabeça [...] temos grandes possiblidade de desenvolver projetos em conjunto com outros departamentos aqui da UFLA [...] e esses programas precisam da parte de gestão e plano de negócios" [...] (Entrevistado 11 )

“O DAE é praticamente minha segunda casa [...], quando não estou em aula, estou cumprindo o horário da bolsa aqui no departamento [...]. O clima aqui é muito gostoso, todos muito amigos e se ajudando [...]". (Entrevistado 21)

“O ponto negativo que eu vejo lá [...] é que é visível uma divisão entre as pessoas [...]. O departamento, ao invés de se unir, parece que sofre com conflitos [...] Aparentemente, por isso, o departamento deu uma estagnada, pois acredito que ele poderia estar muito melhor do que está hoje.”(Entrevistado27 )

O Quadro 1 traz o resultado da análise de conteúdo, com a determinação dos principais fatores internos e externos que afetam o Departamento de Administração e Economia.

Quadro 1 - Análise de SWOT do DAE/UFLA

\begin{tabular}{|c|c|c|c|}
\hline \multirow{2}{*}{ FORÇAS } & FRAQUEZAS & AMEAÇAS & OPORTUNIDADES \\
\hline $\begin{array}{c}\text { Formação e capacitação } \\
\text { do corpo docente. }\end{array}$ & $\begin{array}{c}\text { Ausência de uma } \\
\text { maior proximidade } \\
\text { do departamento com } \\
\text { a sociedade e o } \\
\text { mercado. }\end{array}$ & $\begin{array}{c}\text { A expansão "a todo } \\
\text { custo" do ensino } \\
\text { superior, com súbito } \\
\text { aumento do número de } \\
\text { alunos. }\end{array}$ & $\begin{array}{c}\text { O crescente volume de } \\
\text { investimento do } \\
\text { governo nas } \\
\text { instituições federais de } \\
\text { ensino superior. }\end{array}$ \\
\hline Ambiente & $\begin{array}{c}\text { Desunião e } \\
\text { divergências entre } \\
\text { grupos de } \\
\text { professores. }\end{array}$ & $\begin{array}{c}\text { Desavenças políticas } \\
\text { entre o departamento e } \\
\text { a administração da } \\
\text { universidade. }\end{array}$ & $\begin{array}{c}\text { A criação do parque } \\
\text { tecnológico na } \\
\text { Universidade Federal } \\
\text { de Lavras. }\end{array}$ \\
\hline
\end{tabular}

Fonte: Pesquisa Qualitativa DAE/UFLA, 2013.

A análise de Swot buscou destacar a análise dos ambientes interno e externo ponderando o que foi evidenciado, para a categoria de professores as questões de aproximação do departamento no mercado foi bastante frequente, principalmente com a 
presença do Parque tecnológico. Para os servidores a questão dos investimentos e o ambiente organizacional foram pontos frequentemente encontrados nas entrevistas. Na visão dos alunos a qualidade do ensino e a capacitação do corpo docente foram muito citadas. Houve vários relatos sobre as dificuldades e divergências existentes entre os grupos de professores que foram comuns a todas as categorias.

\subsection{Aplicação do BSC no DAE/UFLA: formulação dos objetivos}

Conforme mencionado anteriormente, neste estudo optou-se por adotar o modelo proposto por Ghelman e Costa (2006a), composto por seis perspectivas (Finanças/Orçamento, Pessoas, Modernização Administrativa, Processos Internos, Clientes e Sociedade/Cidadão).

Foram realizadas perguntas aos entrevistados referentes a cada perspectiva, conforme os questionários apresentados, sendo abordadas a gestão orçamentária, relação interpessoal, imagem institucional, questão dos serviços disponibilizados, a gestão administrativa e através da análise elencou-se as que mais foram citadas dentro de cada contexto. Com base nas informações coletadas nas entrevistas e considerando os aspectos identificados na análise de SWOT, foram formulados dois grandes objetivos básicos para cada uma das perspectivas do modelo adotado. Estes objetivos estão fundamentados na missão, visão e nos valores determinados neste estudo.

a) Perspectiva das Finanças/Orçamento: Os objetivos desta perspectiva estão quase todos diretamente relacionados à Matriz Orçamentária que o Departamento de Administração e Economia dispõe anualmente para arcar com as demandas referentes às atividades dos cursos de graduação. Este recurso custeia as despesas com telefone, fotocópias, serviços gráficos e postais, além da quase totalidade dos materiais de expediente, dos bens permanentes e das diárias utilizadas pelos servidores do departamento.

Neste sentido, é essencial que o departamento procure otimizar os gastos custeados pela Matriz Orçamentária, afim de implantar uma eficiente gestão das despesas, além de procurar diversificar suas fontes de recursos.

b) Perspectiva das Pessoas: No âmbito da UFLA observa-se que o desenvolvimento profissional e a gestão das pessoas que ali trabalham entraram definitivamente na pauta dos assuntos que devem ser tratados com maior dedicação e cuidado pela instituição. Nos últimos anos, foi criada uma pró-reitoria para tratar especificamente dos recursos humanos e foi desenvolvido um programa de capacitação, acompanhado de um calendário de cursos oferecidos pela universidade, elaborado anualmente. 
Além disso, todos os novos servidores que ingressam na universidade passam por um processo de triagem, por meio do qual é identificado qual o local mais adequado para aquele servidor trabalhar. O reflexo dessas políticas voltadas para a gestão de recursos humanos reflete-se também nos setores e departamentos da universidade, e no Departamento de Administração e Economia não é diferente. Estes foram os elementos principais considerados na formulação dos objetivos desta perspectiva.

c) Perspectiva da Modernização Administrativa: Nos últimos anos, a Universidade Federal de Lavras tem procurado investir no processo de adequação de seus procedimentos administrativos, buscando atualizar métodos, modernizar sistemas de assessoramento e desenvolver novas tecnologias que auxiliem os servidores e os alunos na execução de suas atividades. O desdobramento deste processo de modernização atinge diretamente o funcionamento e a gestão dos departamentos didático-pedagógicos, os quais, além de se adequar à nova realidade administrativa, devem criar ferramentas e metodologias de trabalho que facilitem o processo de adaptação a esta nova perspectiva.

Diante de tantas mudanças, é importante que o Departamento de Administração e Economia tenha como objetivo o desenvolvimento de mecanismos que minimizem as dificuldades e potencializem os benefícios desta nova realidade administrativa da universidade.

d) Perspectiva dos Processos Internos: As duas perspectivas anteriores têm ligação direta com esta, uma vez que tanto a modernização das práticas administrativas, quanto a capacitação dos recursos humanos estão fortemente relacionados ao alcance da eficiência na realização de seus processos internos.

Fazer de maneira correta, agir da melhor forma, tomar a decisão mais acertada. A perspectiva dos Processos Internos busca, então, proporcionar condições de o departamento conseguir realizar estas três ações. Nesse sentido, o DAE deve procurar estabelecer objetivos que proporcionem processos internos mais eficientes, que onerem o mínimo possível, ao mesmo passo em que tornem a gestão administrativa mais moderna e organizada.

e) Perspectiva dos Clientes: No caso do Departamento de Administração e Economia, os clientes são os alunos de seus cursos de graduação em Administração e Administração Pública, presenciais, do curso de Administração Pública à distância e também os alunos dos programas de pós-graduação em Administração e Administração Pública. O objetivo máximo nesta perspectiva, conforme destacam Ghelman e Costa (2006a), é proporcionar a satisfação destes alunos e o atendimento de suas necessidades. 
Neste contexto, o modelo de gestão empregado pelo departamento deve ter seu foco nos resultados, primando pela qualidade do serviço prestado (eficácia) e suas iniciativas e ações devem estar na direção deste objetivo.

f) Perspectiva da Sociedade/Cidadão: Nota-se que a missão do Departamento de Administração e Economia, assim como a da própria Universidade Federal de Lavras, tem seu viés social, na medida em que se propõe a formar profissionais altamente capacitados para exercer seu papel na sociedade, além de desenvolver atividades de pesquisa e extensão com retorno para a comunidade. Por esta razão, a Perspectiva da Sociedade/Cidadão é a que se encontra no topo do modelo de Balanced Scorecard proposto, pois o principal objetivo do departamento é alcançar a efetividade no serviço prestado, com foco orientado para o cidadão e para coletividade. Diante de todos os aspectos levantados em cada uma das seis perspectivas do BSC, o Quadro 2 traz os objetivos elaborados para cada uma delas.

Quadro 2. Objetivos para as perspectivas do BSC aplicado ao DAE/UFLA

\begin{tabular}{|c|c|c|}
\hline PERSPECTIVAS & \multicolumn{2}{|c|}{ OBJETIVOS } \\
\hline Finanças/Orçamento & Redução das despesas do departamento & $\begin{array}{c}\text { Aumento dos recursos disponíveis } \\
\text { para custeio }\end{array}$ \\
\hline Pessoas & $\begin{array}{c}\text { Satisfação funcional e crescimento } \\
\text { profissional }\end{array}$ & $\begin{array}{c}\text { Fortalecimento das relações } \\
\text { interpessoais }\end{array}$ \\
\hline $\begin{array}{c}\text { Modernização } \\
\text { Administrativa }\end{array}$ & $\begin{array}{c}\text { Desenvolvimento de novas ferramentas } \\
\text { administrativas }\end{array}$ & $\begin{array}{c}\text { Aumento da atuação das câmaras e } \\
\text { comissões }\end{array}$ \\
\hline Processos Internos & $\begin{array}{c}\text { Dinamização de processos e práticas } \\
\text { internas }\end{array}$ & $\begin{array}{c}\text { Interação entre setores, grupos e } \\
\text { núcleos }\end{array}$ \\
\hline Clientes & $\begin{array}{c}\text { Ampliação das oportunidades de } \\
\text { atividades extracurriculares para os } \\
\text { discentes }\end{array}$ & $\begin{array}{c}\text { Aproximação entre o departamento e } \\
\text { os alunos }\end{array}$ \\
\hline Sociedade/Cidadão & $\begin{array}{c}\text { Aproximação entre departamento, à } \\
\text { comunidade universitária e a sociedade. }\end{array}$ & $\begin{array}{c}\text { Satisfação da sociedade no que se } \\
\text { refere aos serviços prestados pelo } \\
\text { departamento }\end{array}$ \\
\hline
\end{tabular}

Fonte: Pesquisa Qualitativa DAE/UFLA, 2013

Durante o processamento dos objetivos para as perspectivas do BSC foi destacado novamente o padrão de ocorrência efetivamente encontrado nos depoimentos, já que o foco é a busca de objetivos que sejam pontos de concordância entre os entrevistados para todas as categorias. Isso se faz importante exatamente para permitir traçar um mapa estratégico para o departamento. Essa estrutura que contempla os objetivos mais destacados possibilita um plano de ações que tem uma forte adesão entre os integrantes do DAE. Essa condição garante boas perspectivas para a implementação do plano proposto.

\subsection{Mapa estratégico do DAE/UFLA}


A última etapa consiste na construção do mapa estratégico, com a identificação das relações de causa-efeito entre os objetivos em cada perspectiva, e essencialmente, as ligações entre os objetivos de perspectivas diferentes. O mapa estratégico, portanto, é a representação gráfica do Balanced Scorecard e permite uma visualização da estratégia proposta, por meio dessas relações de causalidade entre os elementos de cada perspectiva. Estas ligações repercutem em ações que possibilitam o cumprimento das metas que foram estabelecidas no BSC. O Quadro 3 traz o mapa estratégico do DAE/UFLA com base nos objetivos propostos neste estudo.

Quadro 3 - Mapa estratégico DAE/UFLA

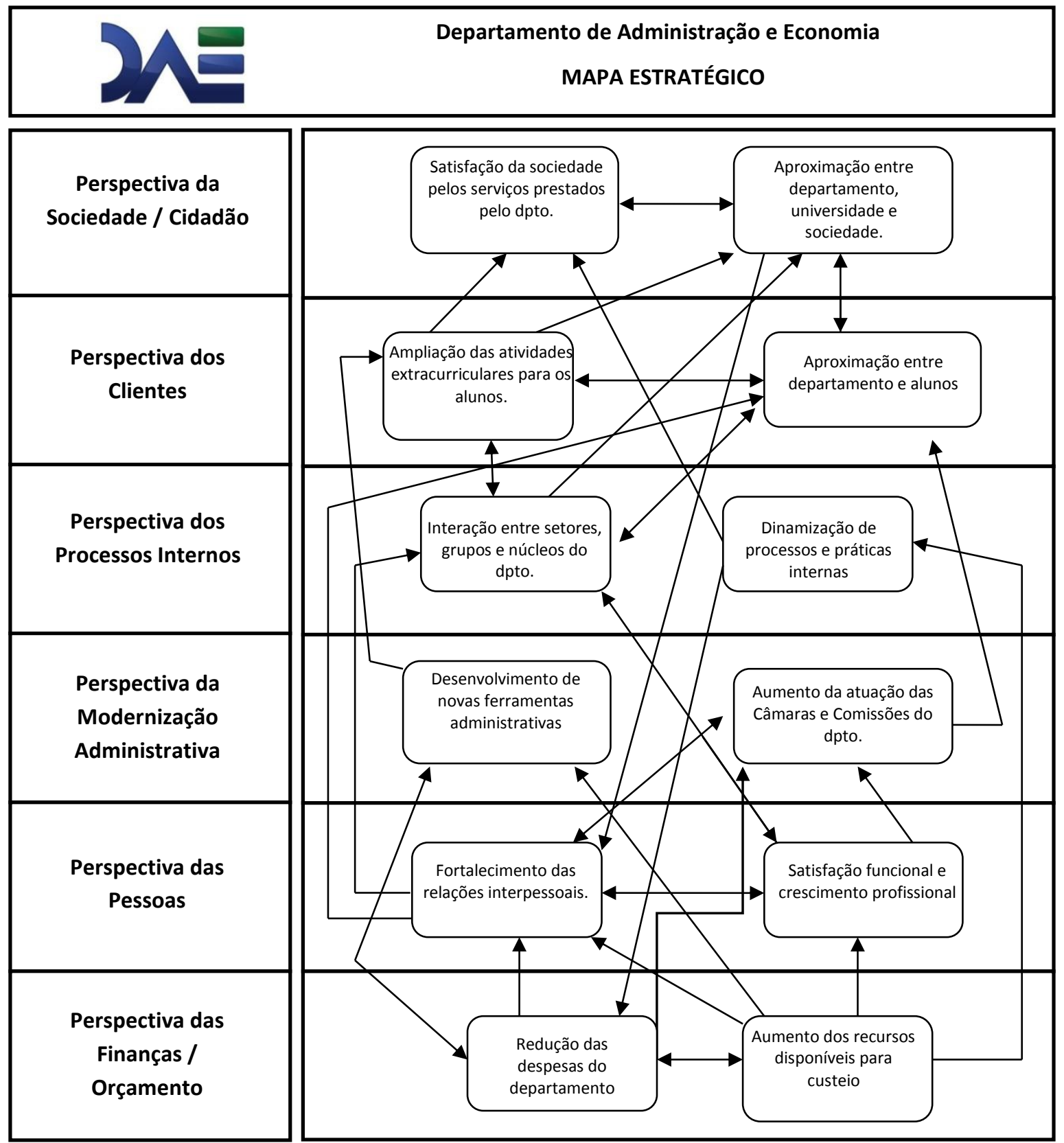

Fonte: Pesquisa Qualitativa DAE/UFLA, 2013. 


\section{CONSIDERAÇÕES FINAIS}

Este trabalho buscou elaborar propostas de objetivos para o planejamento estratégico do Departamento de Administração e Economia da Universidade Federal de Lavras, utilizando-se da metodologia Balanced Scorecard.

No intuito de responder se o BSC é uma metodologia capaz de auxiliar na definição de objetivos no processo de elaboração de um planejamento estratégico para um departamento didático-pedagógico de uma instituição federal de ensino superior, esta pesquisa fez uso da pesquisa documental, observação participante e entrevistas semiestruturadas para conseguir informações e dados suficientes para definir a missão, a visão e os valores do DAE/UFLA, realizar um diagnóstico dos ambientes interno e externo (SWOT) e, por fim, formular objetivos estratégicos para cada uma das seis perspectivas do modelo de BSC adaptado por Ghelman e Costa (2006a) para organizações do setor público.

As constatações extraídas do estudo empírico comprovam que, apesar de a cultura do planejamento não estar incorporada ao DAE, há um cenário favorável ao estabelecimento de um plano de ação para o departamento, com a definição de objetivos e a discussão sobre possíveis estratégias para alcançá-los.

Verificou-se, dentre os vários aspectos identificados nesta pesquisa, que a metodologia Balanced Scorecard tem o potencial para proporcionar uma visão sistêmica da instituição, possibilitando a estruturação de objetivos passíveis de serem vinculados ao desenvolvimento de um planejamento estratégico.

O presente trabalho configura-se como uma pequena contribuição para a investigação sobre o BSC e o desenvolvimento de propostas de planejamento para o setor público. Nesse sentido, sugerem-se novas pesquisas que permitam expandir a aplicação do Balanced Scorecard no DAE/UFLA, nas quais seriam incluídas as definições de metas, indicadores e iniciativas, cuja gama maior de informações proporcionaria mais subsídios para o desenvolvimento de uma gestão estratégica mais efetiva para o departamento. 


\section{REFERÊNCIAS}

CESENA, T. M. Balanced Scorecard para organizações públicas: a experiência da companhia nacional de abastecimento - CONAB. Salvador, 2006.

GHELMAN, S.; COSTA, S. R. R. Adaptando o BSC para o setor público utilizando os conceitos de efetividade, eficácia e eficiência. Anais... III Simpósio de Excelência em Gestão e Tecnologia. Resende-RJ, 2006a.

GHELMAN, S.; COSTA, S. R. R. Adoção do Balanced Scorecard em Organizações Públicas. Anais... III Simpósio de Excelência em Gestão e Tecnologia. Resende-RJ, 2006b.

GIL, A. C. Métodos e técnicas de pesquisa social. $5^{\text {a }}$ ed. São Paulo: Atlas, 1999.

KAPLAN, R. S.; NORTON, D. P. Balanced Scorecard: a estratégia em ação. 7ª ed. Rio de Janeiro: editora Campus, 1997.

KAPLAN, R. S.; NORTON, D. P. Mapas Estratégicos: convertendo ativos intangíveis em resultados tangíveis. 8 ed. Rio de Janeiro: Campus, 2004.

KAPLAN, R. S.; NORTON, D. P. Organização orientada para a estratégia: como as empresas que adotam o Balanced Scorecard prosperam no ambiente de negócios. $10^{\mathrm{a}}$.ed. Rio de Janeiro: Campus, 2000.

KAPLAN, R. S.; NORTON, D. P. The Balanced Scorecard: Measures that Drive Performace. Harvard Business Review 70, no. 1 (January-February): 71-79, 1992.

LAVILLE,C.; DIONNE, J. A construção do saber. Belo Horizonte, editora UFMG, 1999. 340p.

NIVEN, P. R. Balanced Scorecard step-by-step: maximizing performance and maintaining results. New York: John Wiley, 2003.

PINTO, F. J. S. A Avaliação da performance e o Balanced Scorecard no contexto da reforma da Administração Pública. Anais... $2^{\circ}$ Congresso Nacional da Administração Pública INA Centro Congressos Lisboa, 2004.

PINTO, F. J. S. A. Balanced Scorecard: Adaptações ao sector público e às organizações privadas sem fins lucrativos. Anais... III Seminário Internacional Gestão e Estratégia no Século XXI, ESGHT Universidade do Algarve, 2005.

PRIETO,V.C., PEREIRA, F.L.A., CARVALHO, M.M., LAURINDO, F.J.B. Fatores Críticos na implementação do Balanced Scorecard. Revista Gestão \& Produção. São Paulo, v.13, no.1, p.81-92, jan-abr.2006.

RIBEIRO, N. A. B. O Balanced Scorecard e a sua aplicação às instituições de ensino superior público. Braga - Portugal, 2005.

SILVEIRA, H.SWOT. In: TARAPANOFF,K.(org). Inteligência organizacional e competitiva. Brasília:UNB,2001.p.209-226. 
TRIVIÑOS, A. N. S. Introdução à pesquisa em Ciências Sociais: a pesquisa qualitativa em educação. São Paulo: Editora Atlas, 1995.

VERGARA, S. C. Projetos e Relatórios de Pesquisa em Administração. São Paulo: Editora Altas, 2000.

VIDI, F. V. Aplicação do Balanced Scorecard em uma organização pública federal de ensino superior. Estudo de caso: Departamento de Ciências Econômicas da Universidade Federal de Santa Catarina. Florianópolis-SC, 2009.

WEIHRICH,H. The TOWS Matrix: a tool for situational analysis. Long Range Planning, v.15, n.2, p.54-66,1982. 